\title{
COEFFICIENT CONDITIONS FOR STARLIKE FUNCTIONS
}

\author{
by S. RUSCHEWEYH
}

(Received 2 March, 1986)

Let $\left\{a_{k}\right\}$ be a sequence of non-negative real numbers satisfying $a_{1}=1$ and

$$
(k+1) a_{k+1} \leqq k a_{k} \quad(k \in \mathbb{N}) .
$$

Brannan [1] proved that the function

$$
f(z)=\sum_{k=1}^{\infty} a_{k} z^{k}
$$

is close-to-convex univalent in the unit disc $\mathbb{D}$. The example

$$
f(z)=z+\frac{z^{2}}{2}+\frac{z^{3}}{3}
$$

shows that the conclusion in Brannan's theorem is sharp in that sense that "close-toconvex" cannot be replaced by the stronger one: "starlike". It is therefore of interest to see which additional condition can guarantee this stronger conclusion.

THEOREM. Let $a_{k} \geqq 0, a_{1}=1$, satisfy (1) and

$$
(2 k+1) a_{2 k+1} \leqq(2 k-1) a_{2 k} \quad(k \in \mathbb{N}) .
$$

Then the function (2) is starlike univalent in $\mathbb{D}$.

While Brannan's theorem rests on the plain fact that (1) implies

$$
\operatorname{Re}(1-z) f^{\prime}(z)>0 \quad(z \in \mathbb{D})
$$

the proof of our theorem seems to require a fairly deep result of Vietoris [2]:

LemMA 1. Let $b_{0}>0$ and $b_{k}$ a non-increasing sequence of non-negative real numbers satisfying

$$
(2 k) b_{2 k} \leqq(2 k-1) b_{2 k-1} \quad(k \in \mathbb{N}) .
$$

Then, for $n \in \mathbb{N}$

$$
\sum_{k=0}^{n} b_{k} \cos (k \varphi)>0 \quad(0<\varphi<\pi)
$$

and

$$
\sum_{k=0}^{n} b_{k} \sin (k \varphi)>0 \quad(0<\varphi<\pi) .
$$

LEMma 2. Let $f$ be analytic in $\mathbb{D}, f(0)=0, f^{\prime}(0)=1$, and assume, that $f^{\prime}$ is typically real in $\mathbb{D}$ and satisfies $\operatorname{Re} f^{\prime}(z)>0, z \in \mathbb{D}$. Then $f$ is starlike univalent in $\mathbb{D}$.

Glasgow Math. J. 29 (1987) 141-142. 
We recall that a function $F$ is typically real in $\mathbb{D}$ if $\operatorname{Im} F(z) . \operatorname{Im} z>0$ for $z \in \mathbb{D} \backslash \mathbb{R}$. To prove Lemma 2 we write

$$
\frac{f(z)}{z f^{\prime}(z)}=\int_{0}^{1} \frac{f^{\prime}(t z)}{f^{\prime}(z)} d t \quad(z \in \mathbb{D}) .
$$

If $\operatorname{Im} z>0(<0)$ we see that both, $f^{\prime}(t z)$ and $f^{\prime}(z)$, are in the upper (lower) halfplane since $f^{\prime}$ is typically real. But they are also in the right halfplane since $\operatorname{Re} f^{\prime}>0$. This shows that

$$
\operatorname{Re} \frac{f^{\prime}(t z)}{f^{\prime}(z)}>0, \quad 0 \leqq t \leqq 1,
$$

and hence $\operatorname{Re}\left[f(z) /\left(z f^{\prime}(z)\right)\right]>0$ in $\mathbb{D}$, which implies the assertion.

Proof of the Theorem. Since the set of normalized starlike univalent functions is compact it suffices to prove the Theorem for sequences $a_{k}$ satisfying (1), (3), and $a_{k}=0$ for $k \geqq n+1$ for certain $n \in \mathbb{N}$. We then have

$$
f^{\prime}(z)=\sum_{k=0}^{n}(k+1) a_{k+1} z^{k}
$$

Now we write $b_{k}=(k+1) a_{k+1}$ and observe that (1), (3) are precisely the conditions on $b_{k}$ in Lemma 1. (5) and the minimum principle for harmonic functions imply $\operatorname{Re} f^{\prime}(z)>0$, $z \in \mathbb{D}$. Similarly, the minimum principle applied to $\operatorname{Im} f^{\prime}(z)$ and $z \in \mathbb{D}^{+}:=\mathbb{D} \cap\{z: \operatorname{Im} z>$ $0\}$, shows that either $\operatorname{Im} f^{\prime} \equiv 0$ or $\operatorname{Im} f^{\prime}(z)>0$ in $\mathbb{D}^{+}$. In the first case we have $f(z) \equiv z$ and the conclusion is trivial. In the second case, using a reflection at $(-1,1)$, we deduce that $f^{\prime}$ is typically real. Hence Lemma 2 applies to $f$ and the assertion follows.

\section{REFERENCES}

1. D. A. Brannan, On univalent polynomials, Glasgow Math. J., 11 (1970), 102-107.

2. L. Vietoris, Über das Vorzeichen gewisser trigonometrischer Summen, Sitzungsber, Oest. Akad. Wiss., 167(1958), 125-135.

Math. Institut D. Univ.

D-8700 WÜRZBURG

F.R.G. current address

Dept. Matemáticas

UnIVERSIDAD TECNICA F.S.M.

Casilla $110-\mathrm{V}$

VALPARAISO

ChILE 